\title{
Les DRG, un mythe?
}

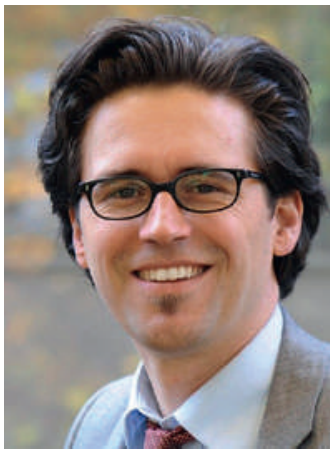

Rouven Porz
Il est évident que le système des DRG n'a rien d'un mythe. Le décompte des coûts hospitaliers via les forfaits par cas depuis janvier 2012 dans nos hôpitaux relève d'une réalité on ne peut plus concrète. Le système SwissDRG a tout juste deux ans et est donc encore très jeune.

Pourtant (ou plutôt à cause de cette introduction récente), il existe déjà de nombreuses histoires sur ce système, plus précisément sur ses possibles conséquences. La plupart de ces commentaires m'apparaissent comme des mythes. Un mythe est par définition une sorte d'association narrative de faits et d'événements apparents, grâce à laquelle les personnes décrivent leur environnement et expriment leur vi- confrontée? Cela ne faisait qu'une semaine qu'elle exerçait à l'hôpital, mais de toute évidence, elle avait déjà été en quelque sorte endoctrinée: ne te préoccupe pas de l'économie, c'est mauvais.

A peine deux jours plus tard, je faisais cours à de jeunes médecins-assistant(e)s. Ayant toujours en tête mon expérience avec les infirmiers, je ne pus m'empêcher de poser la question: «Dans vos nouvelles fonctions professionnelles, quelle est votre expérience du système des DRG?» Etonnement, hochements de tête, stupéfaction. «Quels DRG?» «Je veux dire le nouveau système de décompte dans les hôpitaux.» «Aucune idée, Monsieur Porz, nous n'avons pas le temps de nous en préoccuper.» Je quittai les

\section{«Combien de fables avait-on déjà raconté sur les DRG à cette jeune femme (engagée!) pendant sa formation?»}

sion du monde. Ils ne sont pas rationnels, mais interprétatifs. On connaît plutôt la mythologie religieuse, comme celle de la Grèce antique. Par exemple, dans celle-ci Sisyphe aurait trompé les dieux. Il en fut puni de façon incroyablement sévère. Sans interruption, jour après jour et pendant l'éternité, il dut rouler une lourde pierre en haut d'une montagne des enfers. A peine arrivait-il au sommet que la pierre retombait et Sisyphe devait éternellement recommencer à fournir un immense effort pour hisser en haut de la montagne cette pierre de la taille d'un homme. Bien sûr, il ne s'agit pas d'une histoire rationnelle, mais la signification en est très claire: ne te fâche pas avec les dieux, sinon tu seras puni pour l'éternité.

La semaine dernière, dans le cadre de la formation continue, je donnais un cours d'éthique à de jeunes infirmières et infirmiers. Ils venaient de prendre leurs fonctions à l'hôpital une semaine plus tôt. Ils sortaient directement de leur formation. Premier poste, premier travail, première plongée dans le monde des adultes. Je tentais de différencier éthique et morale personnelle et leur ai demandé ce qui moralement les angoissait dans leur nouveau poste, ce qui les inquiétait. Par quoi pourraient-ils être dépassés? L'une des jeunes m'a répondu spontanément, sans trop réfléchir: «Mon plus grand problème moral, ce sont les DRG.» Frappé de stupeur, je dus un instant me retenir au tableau. J'étais bouleversé et intérieurement, je me demandais: combien de fables avait-on déjà raconté sur les DRG à cette jeune femme (engagée!) pendant sa formation? A combien de mythes avait-elle déjà été médecins-assistant(e)s avec un étrange sentiment. Cette réaction m'avait elle aussi laissé pantois. N'avoir entendu aucune histoire sur les DRG est très révélateur: l'économie est accessoire, seule la médecine pure compte. Je sentais que quelque chose n'allait pas. Certains ont des connaissances farfelues, d'autres ne savent rien, d'autres encore croient tout savoir.

En résumé, il y a urgence à informer! Et de nos jours, les mythes ne sont plus une bonne base de complément d'informations. Devons-nous continuer à hisser la pierre des mythes en haut de la montagne, ou commençons-nous enfin à parler les uns avec les autres au lieu de parler les uns sur les autres? Le 14 novembre 2013 s'est tenu à Zurich un symposium sur le thème «Impact of SwissDRG on patient care» (conséquences du système SwissDRG sur les soins apportés aux patients; voir aussi à ce sujet le texte de N. Biller un peu plus loin dans ce numéro). Les représentantes et représentants des hôpitaux, des universités, de l'OFSP, de la FMH, de l'ASI, de l'ASSM, de SwissDRG et des associations de patients ont enfin parlé ensemble du nouveau système de décompte, au lieu de parler les uns sur les autres. A mon avis, c'est exactement la démarche dont nous avons besoin; ce débat pourrait être source de nouvelles informations. Tout système de financement peut avoir ses points faibles. Mais la gestion de ces questions sensibles ne devrait pas reposer sur des mythes.

Rouven Porz * 